\title{
KINERJA PERAWAT DI RSUD H. PADJONGA DG. NGALLE KABUPATEN TAKALAR
}

\author{
Nurse Performance in Regional Public Hospital Of H. Padjonga Dg. Ngalle \\ Takalar Regency
}

\author{
Rama Nur Kurniawan K, ${ }^{1}$ Khusnul Khatimah Syah ${ }^{2}$ \\ Fakultas Kesehatan Masyarakat Universitas Pancasakti Makassar
}

Korespondensi : rama.nur@unpacti.ac.id

\begin{abstract}
ABSTRAK
Kinerja perawat merupakan ukuran keberhasilan dalam mencapai tujuan pelayanan keperawatan. Penurunan kinerja perawat sangat mempengaruhi citra pelayanan suatu rumah sakit di masyarakat menimbulkan serta kurangnya kepercayaan masyarakat terhadap kemampuan rumah sakit. Berdasarkan survei awal yang dilakukan peneliti di RSUD H. Padjongan Dg. Ngalle Kabupaten Takalar terhadap beberapa perawat pelaksana yang ada di rumah sakit tersebut yang kinerjanya masih kurang atau belum sesuai dengan yang diharapkan, sering terjadi keluhan pasien dalam kegiatan pelayanan di rumah sakit. Penelitian ini bertujuan untuk mengetahui faktor yang berhubungan dengan kinerja perawat di RSUD H. Padjonga Dg. Ngalle Kabupaten Takalar. Jenis penelitian ini menggunakan metode kuantitatif dengan pendekatan cross sectional study, untuk menilai hubungan antara berbagai variabel. Pengumpulan data dengan menggunakan proportional random sampling dengan total sampel sebanyak 153 responden. Pengumpulan data menggunakan kuesioner serta analisis statistik menggunakan uji chi-square dengan tingkat kemaknaan $\mathrm{p}<\alpha(0,05)$. Hasil penelitian menunjukkan bahwa tidak ada hubungan antara kemampuan dan keterampilan dengan kinerja perawat yang ditunjukkan dengan hasil uji statistik dimana nilai $p: 0,910(>\alpha 0,05)$. Tidak ada hubungan antara kepemimpinan dengan kinerja perawat yang ditunjukkan dengan hasil uji statistik dimana nilai $p: 0,249(>\alpha 0,05)$. Ada hubungan antara imbalan dengan kinerja perawat yang ditunjukkan dengan hasil uji statistik dimana nilai $p: 0,038(<\alpha 0,05)$. Ada hubungan antara motivasi dengan kinerja perawat yang ditunjukkan dengan hasil uji statistik dimana nilai $p: 0,010(<\alpha 0,05)$.

Kata kunci : Kinerja perawat, Kemampuan dan ketermapilan, Kepemimpinan, Imbalan, dan Motivasi.

ABSTRACT
Nurse Performance is a measure of success in achieving the goal of nursing services. Decreasing nurse performance greatly influences the image of a hospital's service in the community and creates a lack of public trust in the hospital capacity. Based on the initial survey conducted by researchers at H. Padjonga Hospital Dg. Ngalle Takalar District on some nurses in the hospital whose performance were still lacking or not as expected, complains about hospital services were often articulated by the patients. Objectives To find out what factors related to the performance of nurses in Regional Public Hospital H. Padjonga Dg. Ngalle Takalar Regency. This research uses a quantitative method with a cross sectional study approach to assess the relationship between various variables. The data was collected using proportional random sampling with a total sample of 153 respondents. The data was collected using questionnaires and statistical analysis using chi-square test with significance level $p<\alpha(0.05)$. The results showed that no relationship between abilities and skills and the nurse performance as indicated by the results of statistical tests where the $p$ value is 0.910 (> $\alpha$ 0.05). Similarly, there is also no relationship between leadership and nurse performance as indicated by the results of statistical tests where the $p$ value is $0.249(>\alpha 0.05)$. On the other hand, Rewards appear to be correlated with nurse performance as indicated by the results of statistical tests where the value of $p$ is $0.038(<\alpha$ 0.05). Lastly, there is also a relationship between motivation and nurse performance as indicated by the results of statistical tests where the value of $p$ is $0.010(<\alpha$ $0.05)$.
\end{abstract}

Keywords: Nurse Performance, Ability and Skills, Leadership, Rewards and Motivation. 


\section{PENDAHULUAN}

Kinerja perawat merupakan ukuran keberhasilan dalam mencapai tujuan pelayanan keperawatan. Kinerja perawat dalam pemberian asuhan keperawatan adalah aplikasi kemampuan atau pembelajaran yang telah diterima selama menyelesaikan program pendidikan keperawatan. Kinerja perawat dinilai dari kepuasan pasien yang sedang atau pernah dirawat (Sutrisno, Suryoputro, dan Fatmasari 2017). Kinerja perawat yang kurang dapat disebabkan karena adanya unsur dari luar diri tenaga perawat yang mempengaruhi psikologis sehingga menurunkan semangat kerja. Aspek yang berasal dari luar ini mencakup hubungan interpersonal dengan teman sejawat di tempat kerja, adanya konflik internal keorganisasiaan rumah sakit, kurangnya aspek motorik dari rumah sakit dalam rangka pemberian motivasi kepada tenaga perawat sehingga dapat melaksanakan tindakan asuhan keperawatan yang lebih berkualitas dan menjawab tuntutan masyarakat akan kebutuhan pelayanan (Andi, 2010 dalam Henika, 2016).

Penurunan kinerja perawat sangat mempengaruhi citra pelayanan suatu rumah sakit di masyarakat. Pelayanan keperawatan yang buruk menimbulkan kurangnya kepercayaan masyarakat terhadap kemampuan rumah sakit. Kemampuan dalam melaksanakan tugas merupakan unsur utama dalam menilai kinerja seseorang tetapi tanpa dukungan oleh suatu kemampuan dan motivasi, maka tugas tidak akan dapat terselesaikan (Khalid, 2006 dalam Saleng, 2015).

Mutu pelayanan yang baik tidak sertamerta didapatkan oleh rumah sakit tanpa adanya kerjasama yang baik antar seluruh petugas kesehatan yang ada dalam rumah sakit tersebut. Salah satu petugas kesehatan yang memiliki peranan penting yang ada di rumah sakit adalah perawat. Perawat merupakan ujung tombak dari pelayanan yang diberikan di rumah sakit. Hal ini dikarenakan profesi inilah yang secara langsung berhubungan dengan pasien. Jika kualitas pelayanan yang diberikan oleh perawat baik maka kepuasan dari pasien pun akan meningkat. Oleh karena itu, rumah sakit perlu memberikan perhatian pada kinerja perawat agar perawat dapat terdorong untuk melakukan pekerjaannya dengan baik sehingga mutu pelayanan dapat ditingkatkan. (Kristami, 2008 dalam Lolongan, Balqis and Darmawansyah, 2013).

\section{METODE}

Jenis penelitian ini menggunakan jenis kuantitatif dengan pendekatan cross sectional yaitu pengukuran variabel dilakukan pada suatu saat untuk menilai hubungan antara variabel independen dengan variabel dependen (Hastono, 2007) di RSUD H. Padjonga Dg. Ngalle Kabupaten Takalar. Kegiatan yang dilakukan meliputi pengumpulan data dan pengukuran terhadap variabel dependen dan independen. Penelitian ini menganalisis variabel-variabel yang berhubungan dengan kinerja perawat di ruang rawat inap RSUD $\mathrm{H}$. 
Padjonga Dg. Ngalle Kabupaten Takalar yang dideskripsikan secara kuantitatif menggunakan data primer dari penyebaran kuisioner dan data sekunder dari profil rumah sakit dan data keperawatan.

Populasi pada penelitian ini adalah semua perawat pelaksana yang bertugas di ruang rawat inap RSUD H. Padonga Dg.
Ngalle Kabupaten Takalar adalah sebanyak 246 orang. Penentuan sampel digunakan proporsional random sampling. Mengingat jumlah populasi cukup banyak, sehingga sampel dalam penelitian ini dapat ditentukan dengan perhitungan Slovin, dengan jumlah sampel sebanyak 153 responden.

\section{HASIL}

Tabel 1.

Analisis Hubungan Kemampuan dan Keterampilan Dengan Kinerja Perawat

\begin{tabular}{|c|c|c|c|c|c|c|c|}
\hline \multirow{3}{*}{$\begin{array}{l}\text { Kemampuan dan } \\
\text { Keterampilan }\end{array}$} & \multicolumn{4}{|c|}{ Kinerja Perawat } & \multirow{2}{*}{\multicolumn{2}{|c|}{ Jumlah }} & \multirow{3}{*}{$\boldsymbol{P}$} \\
\hline & \multicolumn{2}{|c|}{ Baik } & \multicolumn{2}{|c|}{ Kurang Baik } & & & \\
\hline & $\mathbf{n}$ & $\%$ & $\mathbf{n}$ & $\%$ & $\mathbf{n}$ & $\%$ & \\
\hline Mampu dan terampil & 144 & 94,1 & 7 & 4,6 & 151 & 98,7 & \\
\hline $\begin{array}{l}\text { Kurang mampu dan } \\
\text { kurang terampil }\end{array}$ & 2 & 1,3 & 0 & 0 & 2 & 1,3 & 0,910 \\
\hline Jumlah & 146 & 95,4 & 7 & 4,6 & 153 & 100 & \\
\hline
\end{tabular}

Berdasarkan tabel 1 di atas menunjukkan bahwa kinerja perawat dengan kategori baik dan memiliki kemampuan dan keterampilan terdapat sebanyak 144 (94,1\%) responden, sedangkan responden dengan kategori kinerja yang kurang baik namun memiliki kemampuan dan keterampilan, terdapat sebanyak $7(4,6 \%)$ responden. Serta kinerja perawat dengan kategori baik namun kurang mampu dan kurang terampil terdapat 2 $(1,3 \%)$ responden.

Tabel 2.

Analisis Hubungan Kepemimpinan dengan Kinerja Perawat

\begin{tabular}{ccccccccc}
\hline \multirow{2}{*}{ Kepemimpinan } & \multicolumn{4}{c}{ Kinerja Perawat } & \multicolumn{2}{c}{ Jumlah } & \multirow{2}{*}{$\boldsymbol{P}$} \\
\cline { 2 - 7 } & \multicolumn{3}{c}{ Baik } & \multicolumn{3}{c}{ Kurang Baik } & & \\
\cline { 2 - 7 } & $\mathbf{n}$ & $\mathbf{\%}$ & $\mathbf{n}$ & $\mathbf{\%}$ & $\mathbf{n}$ & $\mathbf{\%}$ & \\
\hline Baik & 141 & 92,2 & 6 & 3,9 & 147 & 96,1 & \\
Kurang Baik & 5 & 3,2 & 1 & 0,7 & 6 & 3,9 & 0,249 \\
Jumlah & $\mathbf{1 4 6}$ & $\mathbf{9 5 , 4}$ & $\mathbf{7}$ & $\mathbf{4 , 6}$ & $\mathbf{1 5 3}$ & $\mathbf{1 0 0}$ & \\
\hline
\end{tabular}


Berdasarkan tabel 2 di atas menunjukkan bahwa dari 153 responden terdapat sebanyak $141 \quad(92,2)$ responden dengan kriteria factor kepemimpinan baik serta kinerja baik. Kemudian terdapat 6 (3,9\%) responden dengan faktor kepemimpinan baik namun kinerjanya kurang baik. Kemudian terdapat $5(3,2 \%)$ responden dengan faktor kepemimpinan kurang baik namun kinerjanya baik, serta terdapat $1(0,7 \%)$ responden dengan faktor kepemimpinan dan kinerjanya kurang baik.

Tabel 3.

Analisis Hubungan Imbalan dengan Kinerja Perawat

\begin{tabular}{ccccccccc}
\hline \multirow{2}{*}{ Imbalan } & \multicolumn{4}{c}{ Kinerja Perawat } & \multicolumn{2}{c}{ Jumlah } & \multirow{2}{*}{$\boldsymbol{P}$} \\
\cline { 2 - 7 } & \multicolumn{3}{c}{ Baik } & \multicolumn{3}{c}{ Kurang Baik } & & \\
\cline { 2 - 7 } & $\mathbf{n}$ & $\mathbf{\%}$ & $\mathbf{n}$ & $\mathbf{\%}$ & $\mathbf{n}$ & $\mathbf{\%}$ & \\
\hline Sesuai & 101 & 66,0 & 2 & 1,3 & 103 & 67,3 & \\
Tidak sesuai & 45 & 29,4 & 5 & 3,3 & 50 & 32,7 & 0,038 \\
\hline Jumlah & $\mathbf{1 4 6}$ & $\mathbf{9 5 , 4}$ & $\mathbf{7}$ & $\mathbf{4 , 6}$ & $\mathbf{1 5 3}$ & $\mathbf{1 0 0}$ & \\
\hline
\end{tabular}

Berdasarkan tabel 3 di atas menunjukkan bahwa dari total 153 responden terdapat $101 \quad(66,0 \%)$ responden yang imbalannya sesuai serta kinerja baik. Terdapat $2(1,3 \%)$ responden yang imbalannya sesuai namun kinerjanya kurang baik. Kemudian terdapat $45 \quad(329,4 \%)$ responden dengan kriteria kinerja baik namun imbalannya tidak sesuai, serta terdapat $1(0,7 \%)$ responden dengan kriteria imbalan tidak sesuai dan kinerja juga kurang baik.

Tabel 4.

Analisis Hubungan Motivasi dengan Kinerja Perawat

\begin{tabular}{ccccccccc}
\hline & \multicolumn{4}{c}{ Kinerja Perawat } & & \multirow{2}{*}{ Jumlah } & \multirow{2}{*}{$\boldsymbol{P}$} \\
\cline { 2 - 7 } Motivasi & \multicolumn{3}{c}{ Baik } & \multicolumn{3}{c}{ Kurang Baik } & & \\
\cline { 2 - 8 } & $\mathbf{n}$ & $\mathbf{\%}$ & $\mathbf{n}$ & $\mathbf{\%}$ & $\mathbf{n}$ & $\mathbf{\%}$ & \\
\hline Tinggi & 144 & 94,1 & 5 & 3,3 & 149 & 97,4 & \\
Rendah & 2 & 1,3 & 2 & 1,3 & 4 & 2,6 & 0,010 \\
\hline Jumlah & $\mathbf{1 4 6}$ & $\mathbf{9 5 , 4}$ & $\mathbf{7}$ & $\mathbf{4 , 6}$ & $\mathbf{1 5 3}$ & $\mathbf{1 0 0}$ & \\
\hline
\end{tabular}

Berdasarkan tabel 4 di atas menunjukkan bahwa dari total 153 responden terdapat $144(94,1)$ responden dengan krtiteria motivasi tinggi serta kinerja baik. Terdapat 5 $(3,3 \%)$ responden yang motivasinya tinggi namun kinerjanya kurang baik. Kemudian terdapat $2(1,3 \%)$ responden dengan kriteria kinerja baik namun motivasinya rendah, serta terdapat $2(1,3 \%)$ responden dengan motivasi rendah serta kinerja kurang baik. 


\section{PEMBAHASAN}

\section{Hubungan Kemampuan dan Keterampilan Dengan Kinerja Perawat}

Berdasarkan hasil penelitian yang dianalisa menggunakan uji Chi square dengan signifikansi 95\% $(\alpha 0,05)$ dan didapatkan $P$ : $0,910(>\alpha 0,05)$ yang berarti H0 diterima dan Ha ditolak (tidak ada hubungan antara variabel kinerja perawat dengan kemampuan dan keterampilan).

Hasil penelitian ini berbeda dengan penelitian yang dilakukan oleh (Yuliastuti 2007) yang menunjukkan bahwa variabel keterampilan berpengaruh terhadap kinerja perawat dalam penatalaksanaan pasien flu burung, dan juga sejalan dengan penelitian yang dilakukan oleh pitoyo, 2000 yang membuktikan bahwa terdapat hubungan antara kemampuan (pengetahun dan keterampilan) dengan kinerja perawat. Responden dengan kinerja baik namun kemampuan dan keterampilannya kurang, disebabkan akibat jarang diikutkan dalam pelatihan - pelatihan yang terkait dengan tugasnya sebagai perawat pelaksana. Namun perawat tersebut memiliki kemampuan berinteraksi secara positif dengan pasien maupun keluarga pasien, sehingga tidak pernah terjadi keluhan atas penerapan kemampuannya. Menurut (Henry Simamora, 1995 dalam Suprawati et al. 2011) menjelaskan bahwa pelatihan merupakan serangkaian aktivitas yang dirancang untuk meningkatkan keahlian, pengetahuan, pengalaman ataupun perubahan sikap seorang individu atau kelompok dalam menjalankan tugas tertentu.

Responden yang kinerjanya kurang namun kemampuan dan keterampilannya baik disebabkan karena ketidak cocokan dalam tim yang bermula dari ketidak cocokan satu individu dengan individu lain. Hal tersebut membuat beberapa perawat merasa tidak nyaman, tidak adanya tranparansi yang mungkin akan membuat perawat berasumsi mengenai hal yang sedang terjadi, sehingga memungkinkan muncul berbagai rumor yang dapat merusak citra rumah sakit. Selain itu pengaruh keletihan dan kurang istirahat juga dapat mengganggu kesehatan perawat yang mempengaruhi kinerja perawat itu sendiri.

Secara umum kemampuan terbagi menjadi 2 yaitu kemampuan potensi (IQ) dan kemampuan realita (pengetahuan umum dan kemampuan dalam diri sendiri). Kemampuan realita yang dijabarkan adalah skill individu yang dimiliki oleh perawat itu sendiri (Wardani 2011). Keterampilan adalah kecakapan yang berhubungan dengan tugas yang dimiliki dan dipergunakan oleh seseorang pada waktu yang tepat (Gibson, 1988). Perawat yang bertugas memberikan pelayanan kepada masyarakat harus dapat berperilaku profesional. Perilaku profesional dapat ditunjukkan dari memiliki/menerapkan keterampialan profesional keperawatan serta menggunakan etika keperawatan sebagai tuntunan dalam melaksanakan praktek keperawatan dan kehidupan profesioal (Roeles, 1997 dalam Yuliastuti 2007). 


\section{Hubungan Kepemimpinan dengan Kinerja Perawat}

Berdasarkan hasil penelitian yang dianalisa menggunakan uji Chi square dengan signifikansi $95 \%(\alpha 0,05)$ dan didapatkan $P$ : $0,249(>\alpha 0,05)$ yang berarti H0 diterima dan Ha ditolak (tidak ada hubungan antara variabel kinerja perawat dengan kepemimpinan).

Hasil ini sejalan dengan hasil penelitian yang dilakukan oleh (Saleng 2015), tentang faktor-faktor yang berhubungan dengan kinerja perawat di ruang rawat inap rumah sakit khusus daerah Provinsi Sulawesi sElatan bahwa tidak ada hubungan antara kepemimpinan dengan kinerja perawat. Berbeda dengan hasil penelitian yang dilakukan oleh (K, Hamzah, dan Amir 2012) tentang faktor-faktor yang berhubungan dengan kinerja perawat di bagian unit rawat inap rumah sakit umum daya makassar, dimana ada hubungan bermakna antara faktor kepemimpinan dengan kinerja perawat.

Dalam penelitian ini didapatkan bahwa menurut 5 responden yang berhasil diwawancarai, mengatakan bahwa kinerja pemimpinnya kurang kurang mampu memberi arahan dan motivasi kepada anggota timnya, serta sering berlaku tidak adil, arogan dan diskriminatif kepada anggotanya. Jika seorang atasan yang buruk dalam memimpin maka bisa saja mengalami stress atau kurang termotivasi, tentu saja kinerja perawat bisa saja semakin buruk.

Menurut Luthan

kepemimpinan merupakan suatu Black Box atau konsep yang tak bisa dijelaskan,tapi mempunyai pengaruh besar terhadap kinerja karyawan. Sehingga banyak pendekatan dalam mempelajari teori kepemimpinan, ada pendekatan ciri/sifat, pendekatan perilaku, pendekatan kekuasaan-pengaruh, pendekatan situasional dan pendekatan integratif. Agar kepemimpinan benar-benar punya pengaruh terhadap kinerja, mungkin harus dikerucutkan pada satu pendekatan saja.

Sebagai pemimpin, hendaknya seseorang menempatkan dirinya sebagai orang yang bermanfaat untuk orang lain. Dalam bidang keperawatan faktor kepemimpinan dapat memberikan pengaruh yang berarti terhadap kinerja perawat karena pimpinan yang merencanakan, menginformasikan, membuat, dan mengevaluasi berbagai keputusan yang harus dilaksanakan dalam organisasi tersebut. Kepemimpinan dapat memotivasi perawat untuk bekerja dengan penuh semangat sehingga hasil yang ingin dicapai dapat memuaskan perawat maupun rumah sakit. Pemimpin yang berhasil adalah pemimpin yang bisa memahami perilaku, sifat-sifat bawahannya, memiliki perhatian terhadap kemajuan, pertumbuhan dan prestasi bawahannya (Hernika, 2016).

\section{Hubungan Imbalan dengan Kinerja Perawat}

Berdasarkan hasil penelitian yang dianalisa menggunakan uji Chi square dengan signifikansi $95 \%(\alpha 0,05)$ dan didapatkan $P$ : $0,038(<\alpha 0,05)$ yang berarti Ha diterima dan 
H0 ditolak (ada hubungan antara variabel kinerja perawat dengan imbalan).

Hal ini sejalan dengan hasil penelitian yang dilakukan oleh (Hernika 2016), tentang faktor-faktor yang berhubungan dengan kinerja perawat di ruang rawat inap RSUD Cut Nyak Dhien Meulaboh Kabupaten Aceh Barat yang menemukan adanya hubungan antara insentif dengan kinerja perawat. Senada dengan hasil penelitian yang dilakukan oleh (K, Hamzah, dan Amir 2012) yang menunjukkan adanya hubungan antara imbalan dengan kinerja perawat dalam melaksanakan asuhan keperawatan di bagian unit rawat inap Rumah Sakit Umum Daya Makassar. Berbeda dengan hasil penelitian yang dilakukan oleh (Rahayu 2009) yang menyatakan tidak ada hubungan antara system reward dengan kinerja perawat dalam melaksanakan asuhan keperawatan di RSUD Sragen.

Dalam memberikan imbalan, rumah sakit seharusnya mengetahui kebutuhan pegawai. Pada dasarnya perawat yang bekerja di rumah sakit akan selalu memberikan pelayanan yang baik ketika hak dan kewajibannya terpenuhi dengan baik. Namun 45 responden yang meskipun kinerjanya baik tetapi imbalan yang diterimanya tidak sesuai, ini disebabkan karena tugas dan tanggung jawabnya sudah merupakan ketetapan yang berlaku di rumah sakit dan perawat yang termotivasi untuk melakukan asuhan keperawatan karena motif intrinsik, yakni dorongan yang terdapat dari dalam dirinya untuk melakukan pekerjaannya, misalnya: bekerja karena pekerjaan yang dilakukan sesuai dengan bakat dan minat, dapat diselesaikan dengan baik karena memiliki pengetahuan dan keterampilan dalam menyelesaikan dan melaksanakan pendokumentasian asuhan keperawatan serta merasakan bahwa pekerjaan keperawatan yang dilakukan adalah pekerjaan yang mulia. Walaupun imbalan yang diterima tidak sesuai dengan hati nuraninya, dia tetap terpanggil untuk melayani pasien yang membutuhkannya. Adapun 2 responden yang kinerjanya kurang baik namun menurutnya imbalan yang diterima sudah sesui dikarenakan adanya hubungan khusus (kekeluargaan) dengan pihak yang mengatur pembagian imbalan yang bisa disebut sebagai diskriminasi.

Imbalan finansial berupa gaji dan upah memang merupakan salah satu motivator yang kuat bagi seseorang untuk berprestasi karena dengan kenaikan insentif akan membuat seseorang terdorong untuk melakukan yang terbaik dalam pekerjaannya dan sebaliknya jika insentif tidak sesuai dengan yang diharapkan akan menyebabkan motivasi seseorang menurun. Sesuai dengan teori motivasi klasik yang dikemukakan oleh Frederick Taylor yang menyatakan bahwa seseorang akan menurun semangat kerjanya bila upah yang diterima tidak sebanding dengan pekerjaan yang dilakukan. Pemberian insentif yang adil, layak dan tepat waktu juga merupakan daya penggerak yang dapat merangsang terciptanya motivasi karena 
dengan pemberian insentif yang adil, layak dan tepat waktu karyawan merasa mendapat perhatian dan pengakuan terhadap prestasi yang dicapainya (Agus 2013).

\section{Hubungan Motivasi dengan Kinerja Perawat}

Berdasarkan hasil penelitian yang dianalisa menggunakan uji Chi square dengan signifikansi 95\% $(\alpha 0,05)$ dan didapatkan $P$ : $0,010(<\alpha 0,05)$ yang berarti Ha diterima dan H0 ditolak (ada hubungan antara variabel kinerja perawat dengan motivasi).

Hasil penelitian ini sejalan dengan penelitian (Mandagi, Umboh, dan Rattu 2015) yang menunjukkan bahwa terdapat hubungan yang signifikan antara motivasi perawat dengan kinerja perawat dalam menerapkan asuhan keperawatan di Rumah Sakit Umum Bethesda GMIM Tomohon. Serta hasil penelitian yang dilakukan oleh (Parman dan Mitrasari 2017) yang menyatakan ada hubungan yang bermakna antara motivasi dengan kinerja perawat di unit rawat inap RSUD H. Abdul Manap Kota Jambi.

Pada penelitian ini terdapat 5 responden yang kinerjanya kurang namun motivasinya tinggi, hal ini terjadi dimana perawat mampu menciptakan lingkungan kerja yang nyaman, saling melengkapi kebutuhan untuk berkembang namun belum bisa menerapkan kemampuan dan keterampilannya sesuai dengan asuhan keperawatan dalam melayani pasien. Selanjutnya terdapat 2 responden yang kinerjanya baik namun motivasinya rendah, hal ini terjadi dimana perawat mampu menjalin hubungan komunikasi yang baik dalam suatu tim kerja, saling menghargai, proses interaksi antara satu dengan yang lain berjalan dengan baik namun kurang mendapatkan dorongan eksternal seperti imbalan jasa.

Motivasi kerja dapat menumbuhkan semangat dan ketekunan dalam bekerja bagi para petugas untuk selalu meningkatkan kinerja tenaga perawat yang sesuai dengan yang diharapkan. Untuk itu, pimpinan sebagai pengambil keputusan dalam instansi haruslah bisa menyesuaikan antara kepentingan dan kebutuhan organisasi dengan kepentingan dan kebutuhan petugas sehingga secara tidak langsung para petugas dapat selalu meningkatkan kinerja tenaga perawatnya (Saleng 2015).

Dalam hal ini perilaku dari perawat akan baik berasal dari motivasi perawat yang memang baik. Jadi apabila seorang perawat memiliki motivasi yang baik untuk mencapai tujuannya, maka kinerjanya akan meningkat. Meningkatnya kinerja perawat, dalam penelitian ini menyangkut asuhan keperawatan, akan meningkat pula kinerja rumah sakit tersebut. Dengan demikian, makin meningkatnya motivasi perawat secara individu akan meningkatkan kinerja individu, kelompok maupun rumah sakit tersebut (Mandagi, Umboh, dan Rattu 2015). 


\section{KESIMPULAN}

Bedasarkan hasil penelitian dan pembahasan yang telah dikemukakan sebelumnya, maka kesimpulan yang dapat penulis kemukakan adalah sebagai berikut:

1. Pada variabel kemampuan dan keterampilan didapatkan hasil uji Chi square nilai $p=0,910$ dimana nilai $p>\alpha$ $(0,05)$ berarti tidak ada hubungan antara kemampuan dan keterampilan dengan kinerja perawat di RSUD H. Padjonga Dg. Ngalle Kabupaten. Takalar.

2. Pada varibel kepemimpinan didapatkan hasil uji Chi square nilai $p=0,249$ dimana nilai $p>\alpha(0,05)$ berarti tidak ada hubungan antara kepemimpinan dengan kinerja perawat di RSUD H. Padjonga Dg. Ngalle Kabupaten Takalar.

3. Pada variabel imbalan didapatkan hasil ada hubungan antara imbalan dengan kinerja perawat di RSUD H. Padjonga Dg. Ngalle Kabupaten Takalar.

4. Pada variabel motivasididapatkan hasil ada hubungan antara motivasi dengan kinerja perawat di RSUD H. Padjonga Dg. Ngalle Kabupaten Takalar.

\section{SARAN}

Berdasarkan hasil penelitian diatas, maka penulis memberikan saran sebagai berikut:

1. Disarankan kepada pihak RSUD $H$. Padjonga Dg. Ngalle Kabupaten Takalar, agar lebih memperhatikan kemampuan dan keterampilan perawat dalam memberikan pelayanan kepada pasien, salah satunya dengan memberikan pendidikan dan pelatihan - pelatihan yang dapat menunjang dan meningkatkan kinerja perawat.

2. Disarankan kepada pihak RSUD $H$. Padjonga Dg. Ngalle Kabupaten Takalar, sebaiknya mengevaluasi gaya kepemimpinan masing - masing kepala ruangan agar dapat meningkatkan kinerja anggotanya.

3. Disarankan kepada pihak RSUD $H$. Padjonga Dg. Ngalle Kabupaten Takalar agar dapat memperhitungkan imbalan jasa yang diterima perawat serta kelancaran penerimaan imbalan setiap bulan, agar perawat lebih termotivasi sehingga kinerja perawat menjadi lebih baik.

4. Disarankan kepada pihak RSUD $\mathrm{H}$. Padjonga Dg. Ngalle Kabupaten Takalar, agar lebih meningkatkan motivasi kerja tenaga perawat dengan cara memberikan penghargaan kepada perawat yang berprestasi, meningkatkan imbalan jasa serta menciptakan lingkungan kerja yang nyaman, baik dengan pasien, keluarga pasien maupun teman sejawat sehingga dapat menambah kualitas pelayanan kesehataan kepada masyarakat.

\section{DAFTAR PUSTAKA}

Agus, A Haerul. 2013. "Hubungan Motivasi Kerja Dengan Kinerja Perawat Di Rsud Sinjai." Universitas Islam Negeri (UIN) Alauddin Makassar. 
Burhan, Windy Ira Sari, Mulyadi, Dan Rivelino S. Hamel. 2015. "Hubungan Antara Imbalan Jasa Dan Motivasi Kerja Perawat Di Puskesmas Manganitu Kabupaten Sangihe" 3: 1-7.

Dewi, Desi Rosmala, Marina Sulistyati, Dan M Ali Mauludin. 2017. "Hubungan Antara Gaya Kepemimpinan Ketua Umum Dengan Kinerja Karyawan Koperasi," 1-12.

Falaq, Muh. Arief. 2015. "Faktor-Faktor Yang Mempengaruhi Disiplin Kerja Perawat Di RS. Dr. Tadjuddin Chalid Makassar.”

Handayani, Lisda Dwi. 2012. "Mutu Terhadap Pemanfaatan Pelayanan Kesehatan (Studi Analitik Di Puskesmas Mamajang Makassar)." Universitas Veteran Republik Indonesia.

Hasmoko, Emanuel Vensi. 2008. "Analisis Faktor-Faktor Yang Mempengaruhi Kinerja Klinis Perawat Berdasarkan Penerapan Sistem Pengembangan Manajemen Kinerja Klinis (SPMKK) Di Ruang Rawat Inap Rumah Sakit Panti Wilasa Citarum Semarang Tahun 2008." Universitas Stuttgart. Universitas Diponegoro Semarang.

Hera, Rasyidin, Dan Hasmin. 2016. "Pengaruh Konflik Peran Ganda, Beban Kerja Dan Kelelahan Kerja (Burnout) Dengan Kinerja Perawat Wanita Di RSUD I Lagaligo Kabupaten Luwu Timur." Jurnal Mirai Management 1 (1): 119-35.

Hernika. 2016. "RSUD Cut Nyak Dhien Meulaboh Kabupaten Aceh Barat Tahun 2015." Universitas Teuku Umar Meulaboh.

Istikomah, Asih Nor, Wahyu Hidayat, Dan Widayanto. 2014.2 "Pengaruh Keterampilan Kerja, Kompensasi Dan Disiplin Kerja Terhadap Kinerja Perawat (Studi Kasus Rumah Sakit Islam Sultan Agung Semarang Bagian Rawat Inap Unit Umum)." Jurnal Administrasi Bisnis 6: 1-12. Http://Ejournal-
S1.Undip.Ac.Id/Index.Php/.

K, Nurbaya, Hj. Asiah Hamzah, Dan Yusran Amir. 2012. "Faktor-Faktor Yang Berhubungan Dengan Kinerja Perawat Di Bagian Unit Rawat Inap Rumah Sakit Umum Daya Makassar Tahun 2012," 111.

Kambey, Franky V.T, J.M.L Umboh, Dan A.J.M Rattu. 2016. "Faktor-Faktor Yang Berhubungan Dengan Kinerja Perawat Di Rumah Sakit Pancaran Kasih Manado Tahun 2016."

Lolongan, Nenastriyema, Balqis, Dan Darmawansyah. 2013. "Faktor-Faktor Yang Berhubungan Dengan Kinerja Perawat Di Rumah Sakit Umum Daerah Lakipadada Kabupaten Tana Toraja Tahun 2013," 1-11.

Mandagi, Fergie M., Jootje M. L. Umboh, Dan Joy A. M. Rattu. 2015. "Analisis Faktor - Faktor Yang Berhubungan Dengan Kinerja Perawat Dalam Menerapkan Asuhan Keperawatan Di Rumah Sakit Umum Bethesda Gmim Tomohon" 3.

Mathius, Inriyani, Aryanti Saleh, Dan Werna Nontji. 2014. "Faktor-Faktor Yang Berhubungan Dengan Kinerja Perawat Di Ruang Rawat Inap Di Rumah Sakit Bhayangkara Makassar.”

Parman, Dan Reni Mitrasari. 2017. "FaktorFaktor Yang Berhubungan Dengan Kinerja Tenaga Keperawatan Honor Di Unit Rawat Inap RSUD H. Abdul Manap Kota Jambi Tahun 2016" 6 (2): 151-54.

Prasetyo, Ndoni Karang. 2012. "Pengaruh Gaji, Motivasi Dan Gaya Kepemimpinan Terhadap Kinerja Karyawan PT. Dan Liris Divisi Garment Konveksi IV Sukoharjo.”

Rahayu. 2009. "Hubungan Antara Sistem Reward Dengan Kinerja Perawat Dalam Melaksanakan Asuhan Keperawatan Di RSUD Sragen." Berita Ilmu Keperawatan Issn 2 (2): 51-59. Http://Journals.Ums.Ac.Id/Index.Php/Bik 
/Article/View/3792.

Saleng, Muh. 2015. "Faktor-Faktor Yang Berhubungan Dengan Kinerja Perawat Di Ruang Rawat Inap Rumah Sakit Khusus Daerah Provinsi Sulawesi Selatan." Universitas Islam Negeri Makassar.

Sugiarto, Try. 2014. "Pengaruh Motivasi Dan Kemampuan Terhadap Kinerja Pegawai Bagian Umum Dan Keuangan Di Rumah Sakit Umum Daerah (RSUD) Dr. M. Yunus Bengkulu." Universitas Bengkulu.

Suprawati, Atni, Tjahja Bintara, I Made Santu, Dan Sunarti. 2011. "Faktor-Faktor Yang Mempengaruhi Kinerja Perawat Ponkesdes Di Kabupaten Madiun.”

Sutrisno, Yohana Novitasari, Antono Suryoputro, Dan Eka Yunila Fatmasari. 2017. "Faktor-Faktor Yang Berhubungan Dengan Kinerja Perawat Rawat Inap Di RSUD Kota Semarang." Jurnal Kesehatan Masyarakat 5: 142-49.
Undang-Undang No. 44 Tahun 2009. 2009. Undang-Undang Republik Indonesia Nomor 44 Tahun 2009 Tentang Rumah Sakit. Jakarta. Https://Doi.Org/10.1017/Cbo978110741 5324.004.

Wardani, Dwi Puspita Retno. 2011. "Pengaruh Kepemimpinan, Motivasi Kerja, Dan Lingkungan Kerja Terhadap Kinerja Karyawan Pada Rumah Sakit Bhayangkara Semarang Oleh." Fakultas Ekonomi Dan Bisnis.

Yuliastuti, Iing. 2007. "Pengaruh Pengetahuan, Keterampilan Dan Sikap Terhadap Kinerja Perawat Dalam Penatalaksanaan Kasus Flu Burung Di RSUP. H. Adam Malik Tahun 2007.” Universitas Sumatera Utara Medan.

Zuhriana, Nurhayani, Dan Balqis. 2012. "Faktor Yang Berhubungan Dengan Kinerja Perawat Di Unit Rawat Inap Rumah Sakit Umum Daerah ( RSUD) Bula Kabupaten Seram Bagian Timur." 